\section{Estudo \\ Ecidebate}

em CAStão

Plamejamento
Revista Estudo \& Debate, Lajeado, v. 27, n. 1, 2020. ISSN 1983-036X

DOI: http://dx.doi.org/10.22410/issn.1983-036X.v27ila2020.2231

\title{
CONTRIBUIÇÓESS PARA O PLANEJAMENTO ECONÔMICO BRASILEIRO: UMA ABORDAGEM MULTISSETORIAL
}

\author{
Rosa Livia Gonçalves Montenegro ${ }^{1}$, Luiz Carlos de Santana Ribeiro², \\ Samia Mercado Alvarenga ${ }^{3}$
}

\begin{abstract}
Resumo: As primeiras experiências de planejamento ocorreram ao final dos anos 20 no pós-guerra, período que coincide com o surgimento do estado de bem-estar social. Nesse contexto, o Estado passa a intervir fortemente no sistema por meio da formulaçáo e condução de políticas macroeconômicas com intuito de conduzir a economia a estágios superiores de crescimento e desenvolvimento. $\mathrm{O}$ objetivo deste artigo é oferecer direcionamentos de políticas de planejamento para o Brasil, a partir da utilização do instrumental de insumo-produto. Para tanto, utiliza-se a Matriz de Insumo-Produto do Brasil estimada por Guilhoto e Sesso Filho $(2005 ; 2010)$ para o ano de 2013. De forma geral, objetiva-se encontrar evidências empíricas que permitam orientar, por exemplo, decisóes de alocação de investimentos setoriais. Os principais resultados apontaram 15 setores com fortes relaçôes de encadeamento na economia brasileira, os quais devem ser considerados estratégicos do ponto de vista de políticas setoriais que induzam o crescimento econômico.
\end{abstract}

Palavras-chave: Insumo-produto; Índices de ligação; Multiplicadores; Planejamento econômico; Economia brasileira.

\section{CONTRIBUTIONS TO BRAZILIAN ECONOMIC PLANNING: A MULTISECTORAL APPROACH}

Abstract: The first planning experiments occurred in the late 1920s in the post-war period, coinciding with the emergence of the welfare state. In this context, the State starts to intervene strongly in the system through the formulation and conduct of macroeconomic policies in order to lead the economy to higher stages of growth

1 Possui graduação em Ciências Econômicas pela Universidade Federal Rural do Rio de Janeiro (2005), mestrado em Economia Aplicada pela Universidade Federal de Juiz de Fora (2008) e doutorado em Economia pela Universidade Federal de Minas Gerais (2016).

2 Doutor em Economia pelo Centro de Desenvolvimento e Planejamento Regional da Universidade Federal de Minas Gerais - CEDEPLAR/UFMG (2015), com Doutorado-sanduíche na University of Illinois at Urbana-Champaign, mestre em Economia pela Universidade Federal da Bahia (2010) e bacharel em Economia pela Universidade Federal de Sergipe (2007).

3 Doutoranda em Economia no Centro de Planejamento e Desenvolvimento Regional da Universidade Federal de Minas Gerais - CEDEPLAR/UFMG . Mestra em Economia pelo Programa de Pós-Graduação em Economia da Universidade Federal de Sergipe - NUPEC/ UFS (2019). Formada em Ciências Econômicas pela Universidade Federal de Santa Maria - UFSM (2017). 
and development. The purpose of this article is to offer guidelines of planning policies for Brazil, based on the use of input-output instruments. To do so, the Input-Output Matrix of Brazil is estimated by Guilhoto and Sesso Filho $(2005 ; 2010)$ for the year 2013. In general, the objective is to find empirical evidence to guide, for example, allocation of sectoral investments. The main results pointed out 15 sectors with strong linkages in the Brazilian economy, which should be considered strategic from the point of view of sectoral policies that induce economic growth.

Keywords: Input-output; Linkages index; Multipliers; Economic planning; Brazilian economy.

\section{INTRODUÇÃO}

As primeiras experiências de planejamento ocorreram ao final dos anos 20 no pósguerra, período que coincide com o surgimento do estado de bem-estar social ${ }^{4}$. Nesse contexto, o Estado passa a intervir fortemente no sistema por meio da formulaçáo e condução de políticas macroeconômicas com intuito de conduzir a economia a estágios superiores de crescimento e desenvolvimento.

Segundo Lafer (1975), o planejamento consiste em mostrar, a partir do perfil de uma determinada economia, o percurso mais eficiente para atingir o desenvolvimento. Entretanto, cabe investigar se o governo tem à sua disposiçáo técnicas capazes de alocar os recursos de forma a executar as diretrizes elucidadas conforme o planejado. O Brasil, assim como diversos países em desenvolvimento, é um exemplo de processo de planejamento fragilizado seja pela falta de capital humano qualificado, deficiência de aparatos técnicos ou escassez de informaçōes estatísticas (MENDES, 1978).

Deste modo, o presente artigo tem como objetivo oferecer direcionamentos de políticas de planejamento para o Brasil, a partir do instrumental de insumo-produto. Para tanto, utiliza-se a Matriz de Insumo-Produto (MIP) brasileira de 2013, estimada por Guilhoto e Sesso Filho $(2005 ; 2010)$ a partir de dados das Tabelas de Recursos e Usos (TRUs) do Instituto Brasileiro de Geografia e Estatística (IBGE). De forma geral, objetivase encontrar evidências empíricas que permitam orientar, por exemplo, decisões de alocação de investimentos setoriais.

Estudos dessa natureza são relevantes principalmente em decorrência da heterogeneidade setorial brasileira, nos quais os desequilíbrios regionais resultam da concentração de atividades econômicas em áreas já congestionadas (ROSSETI, 1974). Ademais, a decisão setorial de onde investir é tão importante quanto a própria decisão de investir. Logo, a aplicação do modelo de Insumo-Produto é de suma importância para o planejamento econômico, pois oferece mecanismos de análise para alocação eficiente de recursos em áreas pouco desenvolvidas, colocando em evidência a importância das relações estruturais da economia, as quais devem receber a atenção devida dos policy makers (PRADO, 1981).

É válido ressaltar que os modelos de insumo-produto têm sido aplicados nos últimos anos em diferentes áreas como, por exemplo, políticas de mitigação de gases de efeito estufa

4 Pioneiramente a antiga União Soviética utilizou instrumentos de planejamento econômico de forma sistemática. 
e $\mathrm{CO}_{2}$ (VALE et al., 2017; FREITAS et al., 2016), economia do turismo (RIBEIRO et al., 2017; RIBEIRO et al., 2014a; HADDAD et al., 2013), impactos de investimentos em infraestrutura (BELO et al., 2017; RIBEIRO e LEITE, 2014), reciclagem (CARVALHO et al, 2018; RIBEIRO et al., 2014b; IPEA, 2010), entre outras.

Além dessa introdução, o artigo organiza-se em mais três tópicos. O segundo item faz uma breve revisão do modelo de insumo-produto, enfatizando sua utilização como instrumento de planejamento. Na terceira seçâo faz-se a descrição dos métodos de análise utilizados, cujos resultados são apresentados e discutidos na seção subsequente, seguida dos comentários finais e direcionamentos para as políticas de planejamento.

\section{REVISÃO DE LITERATURA: PLANEJAMENTO ECONOMICO E A APLICAÇÃO DE INSUMO-PRODUTO COMO INSTRUMENTO}

Os anos compreendidos entre o final da década de 40 e o início do pós-guerra foram marcados pela autonomia dos planejadores de política econômica, período este também reconhecido como a era de ouro (golden era) do planejamento (CAMPBELL e FAINSTEIN, 1996; HALL, 2002). O planejamento como estratégia de desenvolvimento ganhou força em função da ineficiência dos processos econômicos em promover equidade socioeconômica e garantir o uso sustentável dos recursos ambientais (HEALEY, 2005).

Do ponto de vista neoclássico "o planejamento é concebido como uma administração racional, isto é, um processo de distribuição ótima dos recursos e dos meios de produção" (CARDOSO, 1975, p. 162). Sob a ótica marxista, o planejamento é tido como mero instrumento para manter o status quo capitalista (SOUZA, 2006). Desse modo, a escolha ou a priorização dos objetivos seriam resultados de decisóes políticas que favoreceriam determinados grupos em detrimento de outros (CARDOSO, 1975; LAFER, 1975). Assim, Cardoso (1975) argumenta que o planejamento, especialmente o planejamento econômico, seria viável apenas em sociedades socialistas, visto que não haveria dominação de uma classe sobre a outra nem existiria a figura do Estado a promover ou respaldar esta dominação.

Nos últimos 30 anos, o planejamento tem sofrido críticas de origens diversas. Souza (2006) as divide em duas vertentes: marxistas e conservadoras. Um dos principais pontos da crítica marxista é a concepção da Economia Urbana neoclássica em admitir que a sociedade seja formada por um agregado de indivíduos/consumidores. Por outro lado, a crítica conservadora é baseada na insatisfação com a intervenção estatal keynesiana, a qual foi incapaz, por meio dos mecanismos de auto regulação, de evitar crises.

$\mathrm{Na}$ década de 1970, após o primeiro choque do petróleo e o agravamento da crise do sistema capitalista, os fundamentos keynesianos baseados na sustentaçáo do crescimento econômico a partir dos elevados gastos sociais oriundos do Estado, dão espaço para as objeçóes neoliberais que clamam por um estado mínimo e um mercado livre (SOUZA, 2006). No início dos anos 80 , com a ascensão ao poder de uma nova direita, representada por Margareth Thatcher na Inglaterra e Ronald Reagan nos Estados Unidos, o neoliberalismo se fortalece como uma maneira de transformar a governança e torná-la mais relevante na dinâmica das economias contemporâneas. 
O "thatcherismo", mesmo com seu apelo desregulamentador, priorizou os planejamentos econômico, ambiental e o ordenamento do território como uma meta a ser atingida durante sua administração (HEALEY, 2005). Todavia, o idealismo neoliberal hegemônico somado à crise do estado de bem-estar social (welfare state) propóe o retorno do mercado como organizador chave da vida econômica o que enfraquece o planejamento, a medida que, este era fortemente vinculado a um estado intervencionista (SOUZA, 2006).

Contudo, Cardoso (1975) salienta que para uma sociedade sobreviver e crescer é preciso planejar, mesmo em economias capitalistas, em que o planejamento aparece como variável de resposta técnica e política para o desafio das sociedades industriais. Partindo desta lógica, o objetivo do planejamento ou da intervenção estatal é criar condiçóes para a sobrevivência do sistema a longo prazo (SOUZA, 2006).

No Brasil, antes dos anos 30, a intervenção do estado no sistema econômico se baseava na ideologia do laissez-faire, que preconizava intervenção mínima. A participação estatal direta, no que tange a assuntos econômicos, resumia-se ao setor financeiro, cujo principal canal de atuação era o Banco do Brasil. Outras ações mais incisivas por parte do Estado estavam direcionadas a proteção da indústria nascente, tal como a cobrança de impostos de importação (MAIA, 2014).

A Revolução de 1930 e a Grande Depressão contribuíram para a conscientização dos problemas nacionais, principalmente, no tocante ao modelo econômico agrárioexportador. A partir disso, houve aumento do intervencionismo estatal e a condenação do liberalismo. Nesse momento, e as mudanças no sistema socioeconômico e político brasileiro criaram as condiçóes necessárias para que o planejamento integrasse a política econômica governamental (MENDES, 1978).

Para Mendes (1978), o planejamento econômico praticado no Brasil ao longo do século XX pode ser analisado com vistas aos planos nacionais, tais como: Programa de Metas (1957-61), o qual representa o início da experiência brasileira de planejamento econômico, Plano Trienal de Desenvolvimento Econômico e Social (1963-65), Plano de Ação Econômica do Governo (1964-66), Plano Estratégico de Desenvolvimento (196870), Programa de Metas e Bases para a Ação do Governo (1970-72), I Plano Nacional de Desenvolvimento (1972-74) e II Plano Nacional de Desenvolvimento (1975-79). Com exceção do II PND, tais planos eram de curto-prazo tendo duração média de dois anos.

A respeito dos planos nacionais a longo prazo, é valido ressaltar que políticas, principalmente as industriais e voltadas à inovação, exigem um foco em resultados visíveis e com investimentos significativos. Para o desenvolvimento de inovaçóes tecnológicas, países desenvolvidos, por exemplo, possuem um quadro de ciência básica desenvolvido e um sistema de inovação aprimorado. No caso do Brasil, a presença do Estado fornece suporte ao fomento de atividades inovadoras. Paralelamente, esse apoio garante que políticas públicas nessa direção promovam, em nível inferior aos países desenvolvidos, o desenvolvimento de pesquisas em laboratórios, universidades, criando uma condição mínima de sobrevivência do sistema de inovação brasileiro (DE NEGRI, 2017). O fato é que para garantir a superação do atraso da base tecnológica brasileira e garantir a uma competitividade industrial compatível com as grandes naçóes, são necessários investimentos de médio e longo prazo, em setores capazes de produzir tecnologia de ponta. 
Da mesma forma, as políticas de planejamento relativos ao impacto dos investimentos em P\&D nos setores de agricultura, transporte, energia e telecomunicaçóes, por configurarem-se em setores estratégicos, possuem um poder de amplificar os efeitos desses investimentos. Em outras palavras, as decisóes das firmas em investir em P\&D estão atreladas em seu retorno privado. Logo, quando o governo concede incentivos à iniciativa privada, os resultados surgem via a taxa de retorno social'5(MENEZES FILHO et al, 2014). Tais políticas são aplicadas via políticas diretas (funding direto por parte do governo para laboratórios, universidades ou empresas, investimento na formação de capital humano) e políticas indiretas (fomentam a competição e regulação, em particular nas indústrias com alto P\&D, como a farmacêutica e a de telecomunicaçóes) (MENEZES FILHO et al., 2014).

A despeito disso, almeja-se que políticas regionais que selecionam setores ou indústrias privilegiadas, por intermédio das políticas de planejamento, também sejam capazes de orientar um debate pautado no estabelecimento da coesão social, e no encontro de valores sociais e institucionais. O cenário atual confirma a ruptura de políticas tradicionais de planejamento, e não se observa um espaço adequado para atenuar as disparidades regionais (ROCHA NETO e BORGES, 2011).

Por outro lado, os grandes projetos de investimentos, objeto dos vários planos nacionais, geralmente eram direcionados para energia, transporte e infraestrutura (LAFER, 1975). Isso porque, acreditava-se que o direcionamento dos investimentos para setores considerados estratégicos provocaria a expansão de outras atividades e efeitos de encadeamento. Contrariamente, Bernardes (1986) ressalta que essas políticas setoriais não levam em consideração o impacto sobre a configuração do espaço, além de que a implementação dos planos poderia acirrar as disparidades regionais (VAINER, 2007; MENDES, 1978).

Quando se modifica o valor de uma variável qualquer do sistema econômico, seja em sua magnitude real ou monetária, o valor de muitas outras se modifica. Logo, a promoção do crescimento de um setor carece da verificaçáo dos efeitos e repercussóes que possivelmente podem ocorrer como consequência dessa decisão, em cada um dos demais setores da economia. Essa característica é visível por meio das propriedades da matriz Inversa de Leontief que será especificada na próxima seção.

Uma valiosa ferramenta para auxiliar a elaboração de planejamento econômico são os modelos de insumo-produto, desenvolvidos a partir da teoria de equilíbrio geral de Walras, os quais permitem verificaçóes de interdependência setoriais (STONE, 1984). Originalmente, o sistema de representação do princípio da interdependência foi concebido por Leontief como sendo uma adaptação da teoria neoclássica de equilíbrio geral ao estudo empírico da interdependência de quantidade entre atividades econômicas inter-relacionadas (LEONTIEF, 1966).

Leontief desenvolveu modelos no âmbito regional e mundial, nesta última área a utilização de insumo-produto recebeu maior destaque (MILLER e BLAIR, 2009). Assim,

5 Impacto das atividades de P\&D realizadas em uma firma sobre as atividades de outras firmas. (MENEZES FILHO et al., 2014). 
de acordo com o objeto de estudo do pesquisador as matrizes de IP podem ser regionais ou inter-regionais. As primeiras avaliam uma determinada regiáo, como o Brasil ou alguma Unidade da Federação, por exemplo. Já as inter-regionais são compostas por duas ou mais regiōes como, por exemplo, Minas Gerais e o restante do Brasil, possibilitando avaliar o impacto de Minas Gerais no restante do Brasil e de forma análoga, do restante do Brasil em Minas Gerais, em todos os setores presentes na matriz.

$\mathrm{O}$ aumento do interesse pela análise regional induziu modificações no modelo de insumo-produto, as quais foram necessárias para captar particularidades inerentes às questôes regionais. Rosseti (1974) informa que esta modelagem adentrou no Brasil durante a concepção do Plano de Metas em 1956, quando o manual da CEPAL "Introducción a la técnica de programación" difundiu a metodologia de programação mesmo com matrizes pouco detalhadas devido à falta de informaçóes estatísticas.

No Brasil as matrizes de insumo-produto são elaboradas e divulgadas pelo IBGE desde 1970, com periodicidade quinquenal. As matrizes divulgadas a partir dessa data já adotaram as novas recomendaçóes sobre o sistema de contas nacionais, elaborado pela Organização das Nações Unidas (SNA, 1993). É importante ressaltar que a matriz utilizada no presente trabalho já segue as recomendaçōes mais recentes de 2008 da ONU.

\section{MATERIAIS E MÉTODOS}

Com intuito de atingir os objetivos propostos, faz-se uso da técnica de insumoproduto proposta por Leontief (1966) baseado em um modelo linear de produção em que o sistema econômico é representado de maneira simplificada através de quadros de fluxos intersetoriais de bens e serviços (PRADO, 1981). Essa estrutura visa atender o consumo intermediário entre indústrias e a demanda final da economia (STONE, 1968). Assim, matematicamente, um modelo de $n$ setores pode ser expresso como:

$$
X_{i}=\sum_{j}^{n} X_{i j}+\left(C_{i}+I_{i}+G_{i}+E_{i}\right) ; \forall_{i, j}=1, \ldots, n .
$$

Em que:

$X_{i}=$ Produto bruto;

$\sum_{j}^{n} X_{\ddot{j}}=$ Demanda Intermediária;

$\left(C_{i}+I_{i}+G_{i}+E_{i}\right)=$ Demanda Final.

A equação 1 pode ser reescrita como:

$$
X-A X=Y
$$

Sendo que $A=\left[a_{i j}\right]$ é a Matriz Tecnológica que exibe o valor do conjunto de produtos do setor $i$ diretamente adquiridos para a produção de uma unidade monetária de 
produtos do setor $j$ e $Y$ é a demanda final. A partir de manipulações algébricas na equação 2, chega-se à solução do modelo (4).

$$
\begin{aligned}
& (I-A) X=Y \\
& X=(I-A)^{-1} Y
\end{aligned}
$$

Sendo que $B=(I-A)^{-1}$ é a Matriz Inversa de Leontief. Cada elemento dessa matriz representa as necessidades diretas e indiretas (totais) do setor $i$ por unidade de demanda final em termos do produto do setor $j$.

Para desenvolver este estudo, adota-se a matriz de insumo-produto do Brasil de 2013, estimada por Guilhoto e Sesso Filho $(2005 ; 2010)$ a partir das TRUs do IBGE, desagregadas em 68 atividades econômicas e 128 produtos, resultando em uma MIP, setor $\mathrm{x}$ setor, de dimensóes $68 \times 68$. Complementarmente utilizam-se os índices de ligação de Hirschman-Rasmussen (HR), índices puros de ligação e campo de influência para identificar quais setores têm forte poder de encadeamento e estabelecer os setores-chave da estrutura produtiva. A definiçấo dos índices de ligação interindustriais é de suma importância para a adoção e implementação de estratégias de planejamento setorial.

Os coeficientes inspirados por Rasmussen (1956) e aplicados por Hirschman (1958), aqui chamados de índices de ligação de $\mathrm{HR}$, mostram a relaçáo da média dos impactos do setor com a média total da economia. $\mathrm{O}$ índice de HR para trás, matematicamente, pode ser escrito da seguinte forma:

$$
U_{o j}=\frac{\frac{1}{n} B_{o j}}{\frac{1}{n^{2}} \sum_{i=1}^{n} B_{o j}}
$$

Em que, $U_{o j}$ é o Coeficiente de Ligaçáo de HR para trás, ou à montante; $B_{o j}$ é um vetor linha, $B_{o j}=\sum_{i=1}^{n} b_{i j}$, o qual soma os valores das linhas da Matriz Inversa de Leontief (B) ao longo de suas colunas, mostrando quanto é demandado por cada setor em seus encadeamentos para trás. $\mathrm{O}$ índice de HR para frente é definido como:

$$
U_{i o}=\frac{\frac{1}{n} B_{i o}}{\frac{1}{n^{2}} \sum_{j=1}^{m} B_{i o}}
$$

Sendo que $U_{i o}$ é o Coeficiente de Ligação de HR para frente, ou a jusante; $B_{i o}$ é um vetor coluna, $B_{i o}=\sum_{j=1}^{m} b_{i j}$, que soma os valores das colunas da Matriz Inversa de Leontief (B) ao longo de suas linhas, mostrando o quanto é ofertado por cada setor em seus encadeamentos para a frente. 
Embora os índices de HR sejam amplamente utilizados para a identificação de setoreschave, eles têm recebido críticas por não considerarem a influência dos diferentes níveis de produção em cada setor da economia. No intuito de suprir essa deficiência metodológica, são apresentados os índices puros de ligações, também denominado GHS (GUILHOTO et al., 2005).

A técnica GHS resulta de uma série de decomposiçóes da Matriz Inversa de Leontief. Tais índices são denominados PBL (pure backward linkage) e PFL (pure forward linkage) que, de forma resumida, são expressos pelas equaçóes 7 e 8 .

$$
\begin{aligned}
& P B L=\Delta_{r} A_{r j} \Delta_{j} Y_{j} \\
& P F L=\Delta_{j} A_{j r} \Delta_{r} Y_{r}
\end{aligned}
$$

O PBL indica o impacto do valor da produção total do setor $j$ sobre o resto da economia, livre da demanda de insumos que o setor $j$ produz para ele mesmo e dos retornos do resto da economia para o setor $j$ e vice-versa. O PFL, por sua vez, aponta para o impacto do valor da produçáo total do resto da economia sobre o setor $j$. Pode-se, ainda, obter o índice puro total das ligaçôes (PTL) por meio da soma do PBL e do PFL, uma vez que são expressos em valores correntes:

$$
P T L=P B L+P F L
$$

Os índices de ligação puros normalizados consideram o peso de cada setor como demandante ou ofertante na economia e o seu respectivo tamanho relativo, permitindo assim analisar a importância do setor. Nestes índices, é possível observar o impacto puro de um setor sobre o resto da economia, e devido à normalizaçáo, pode-se fazer uma análise comparativa com os índices de HR apresentados. O PBLN considera o setor como demandante, ou seja, avalia o setor na economia. O PFLN analisa o setor como ofertante, ou seja, analisa como a economia depende desse referido setor.

Por conseguinte, no intuito de identificar os principais elos que podem provocar maiores impactos sobre a economia brasileira a partir de suas relações intersetoriais, é apresentada também a abordagem do campo de influência desenvolvida por Sonis e Hewings (1989). Para se calcular o campo de influência é necessária a utilização da Matriz de Coeficientes Técnicos (A), de uma Matriz de variaçóes incrementais (E) e da Matriz Inversa de Leontief - $B=(I-A)^{-1}$.A avaliação do impacto dessas variaçóes em cada um dos elementos da Matriz $A$, deverá ocorrer uma pequena variação $\varepsilon$, em cada $a_{i j}$ isoladamente, ou seja, $\Delta A$ é uma matriz $E=\left|\varepsilon_{i j}\right|$, tal que ${ }^{6}$ :

$$
\varepsilon_{i j}=\left\{\begin{array}{l}
\varepsilon \text { se } i=i_{1} \text { e } j=j_{1} \\
0 \text { se } i \neq i_{1} \text { e } j \neq j_{1}
\end{array}\right.
$$

6 Adotou-se um $e=0.001$. 
Assim, uma variação de magnitude $\Delta A$ nos Coeficientes da Matriz $A$, resulta numa nova Matriz de Coeficientes Técnicos: $A^{*}=A+\Delta A$. Desta forma, a Matriz $B$ pode ser reescrita como: $B^{*}=(I-A-\Delta A)^{-1}$. O campo de influência de cada coeficiente é aproximadamente igual a:

$$
F\left(\varepsilon_{i j}\right)=\frac{B^{*}-B}{\varepsilon_{i j}}
$$

Desta forma, a influência total de cada coeficiente técnico, ou de cada elo da matriz insumo-produto é dada por:

$$
S_{i j}-\sum_{k=1}^{n} \sum_{l=1}^{n}\left[f_{k l}\left(\varepsilon_{i j}\right)\right]^{2}
$$

Portanto, quando maior for $S_{i j}$ maior é o campo de influência do coeficiente $\mathrm{a}_{\mathrm{ij}}$ sobre a cadeia produtiva.

Por fim, os multiplicadores de impacto são utilizados para avaliar o impacto de mudanças exógenas sobre o produto, a renda, o emprego, valor adicionado, impostos, entre outras variáveis. Desta forma, é possível observar como as variaçóes na demanda final afetam a economia e, principalmente, como estes efeitos são distribuídos entre os setores.

Dessa forma, considera-se não apenas o efeito direto sobre a produção do setor, mas o efeito indireto gerado em decorrência das relaçóes intersetoriais de oferta e demanda de insumos. No presente estudo são calculados os multiplicadores sobre a produção, o emprego e a renda. $\mathrm{O}$ multiplicador do produto do setor $j\left(M P_{j}\right)$ pode ser definido como o total necessário de produção de todos os setores, para satisfazer a variação em uma unidade monetária da demanda total do setor $j$ (MILLER e BLAIR, 2009), e expresso por:

$$
M p_{j}=\sum_{i=1}^{n} b_{i j}
$$

Em que $b_{i j}$ são os elementos da Matriz Inversa de Leontief. Quanto maior for o multiplicador do produto, maiores serão os efeitos de aumento na demanda final de um setor para a economia como um todo em termos de valor bruto da produção. $\mathrm{O}$ resultado do multiplicador do produto pode ser transformado em termos de geraçáo de emprego por meio do coeficiente de emprego do setor $i\left(e_{i}\right)$, definido por:

$$
e_{i}=\frac{w_{i}}{x_{i}}
$$

Em que $w_{i}$ é o número de trabalhadores empregados no setor $i$ e $x_{i}$ é a produção total do setor $i$. Assim, o multiplicador do emprego simples do setor $j\left(M P_{j}\right)$ corresponde ao número de postos de trabalho criados em toda a economia, quando aumenta em uma unidade monetária a demanda do setor $j$. O multiplicador de emprego simples, para uma economia com dois setores, pode ser especificado como: 


$$
\begin{aligned}
& E=\hat{w} \cdot(I-A)^{-1} \\
& E=\left[\begin{array}{ll}
e_{1} & 0 \\
0 & e_{2}
\end{array}\right]\left[\begin{array}{ll}
b_{11} & b_{12} \\
b_{21} & b_{22}
\end{array}\right] \\
& E_{1}=e_{1} b_{11}+e_{2} b_{21} \text { e } E_{2}=e_{1} b_{12}+e_{2} b_{22}
\end{aligned}
$$

Em que: $E_{1}$ e $E_{2}$ são os multiplicadores simples de emprego dos setores 1 e 2, respectivamente.

O multiplicador simples de renda busca determinar quais os impactos de variaçóes na demanda final sobre a renda recebida pelas famílias. De forma geral, a especificação matemática é a mesma apresentada para o multiplicador de emprego utilizando o coeficiente de renda.

Enquanto o critério do multiplicador de produto é de caráter quantitativo, isto é, tido como principal indicador de crescimento, os multiplicadores de emprego e de renda são os principais indutores ao desenvolvimento econômico, configurando-se, assim, em termos qualitativos para a economia (RIBEIRO e LEITE, 2012). Os multiplicadores utilizados no presente trabalho se restringem à demanda de insumos intermediários, isto é, a demanda das famílias é exógena ao sistema, por isso os multiplicadores apresentados aqui são chamados de simples (GUILHOTO et al., 2010).

\section{RESULTADOS E DISCUSSÓES}

A Tabela 01 apresenta os resultados dos índices de ligaçâo de HR e dos índices puros. Para o primeiro índice, 11 setores foram classificados como chave, isto é, apresentaram o índice de ligação para frente e para trás superiores a 1, são eles: Fabricação de celulose, papel e produtos de papel, Refino de petróleo e coquerias , Fabricação de químicos orgânicos e inorgânicos, resinas e elastômeros , Fabricação de defensivos, desinfetantes, tintas e químicos diversos , Fabricação de produtos de borracha e de material plástico , Produção de ferrogusa/ferroligas, siderurgia e tubos de aço sem costura, Fabricação de produtos de metal, exceto máquinas e equipamentos, Energia elétrica, gás natural e outras utilidades, Transporte terrestre, Telecomunicaçōes e Outras atividades profissionais, científicas e técnicas.

A principal desvantagem dos índices de HR é que eles não levam em conta o tamanho do setor na economia. Ou seja, determinado setor pode ter encadeamento para trás e para frente acima da média, mas ter uma baixa participação na produção total da economia. Sendo assim, utiliza-se de forma complementar os índices puros de ligação.

A fim de comparar os índices puros com os de ligação de HR, normalizaram-se os primeiros e adotou-se a interpretação apresentada por Haddad (1995), o qual classifica como índices fortes aqueles que possuem resultados maiores do que a média somada mais duas vezes o desvio padrão da amostra. Desta forma, os setores que se destacam em relaçáo ao índice puro normalizado para trás (PBL) são: Fabricação de automóveis, caminhōes e ônibus, Construção $(7,84)$, Administraçáo pública, defesa e seguridade social $(4,90)$, Abate e produtos de carne, inclusive os produtos do laticínio e da pesca $(4,76)$, Comércio por 
atacado e a varejo, exceto veículos automotores (4,65), Fabricação de automóveis, caminhóes e ônibus, exceto peças $(4,29)$. Tais setores apresentam elevado impacto puro do valor de sua produçáo, demandando de forma expressiva dos demais setores da economia brasileira.

Do ponto de vista do índice puro normalizado para frente (PFL), os setores que se destacam são: Comércio por atacado e a varejo, exceto veículos automotores $(6,73)$, Intermediação financeira, seguros e previdência complementar $(4,32)$, Refino de petróleo e coquerias $(3,71)$, Transporte terrestre $(3,56)$, Extração de petróleo e gás, inclusive as atividades de apoio $(2,94)$. Esses setores são os que mais geram produçáo para os demais setores da economia brasileira.

A partir dos índices puros normalizados totais, pode-se analisar o impacto conjunto na economia de cada setor como demandante e ofertante. A partir deles é possível definir os setores-chave como aqueles que apresentaram os maiores índices (acima da média mais 2 vezes o desvio padrão da amostra). Dentre os setores da economia brasileira que possuem tal característica destaca-se: Comércio por atacado e a varejo, exceto veículos automotores $(5,69)$, Construção $(4,38)$, Intermediação financeira, seguros e previdência complementar $(2,97)$, Refino de petróleo e coquerias $(2,93)$, Administração pública, defesa e seguridade social $(2,65)$.

Tabela 01- Resultados dos índices de ligação de HR e dos índices puros

\begin{tabular}{|c|c|c|c|c|c|c|}
\hline \multirow{2}{*}{\multicolumn{2}{|c|}{ Setores }} & \multicolumn{2}{|c|}{$\begin{array}{l}\text { Índices de } \\
\text { ligaçáo HR }\end{array}$} & \multicolumn{3}{|c|}{$\begin{array}{c}\text { Índices puros de } \\
\text { ligaçáo }\end{array}$} \\
\hline & & BL & FL & PBL & PFL & PTL \\
\hline 1 & Agricultura, inclusive o apoio à agricultura e a pós-colheita & 0.91 & 1.86 & 1.59 & 2.68 & 2.14 \\
\hline 2 & Pecuária, inclusive o apoio à pecuária & 0.98 & 0.90 & 0.53 & 1.59 & 1.06 \\
\hline 3 & Produção florestal; pesca e aquicultura & 0.77 & 0.78 & 0.09 & 0.28 & 0.18 \\
\hline 4 & Extração de carvão mineral e de minerais não-metálicos & 1.01 & 0.70 & 0.03 & 0.36 & 0.19 \\
\hline 5 & Extração de petróleo e gás, inclusive as atividades de apoio & 0.80 & 1.74 & 0.38 & 2.94 & 1.65 \\
\hline 6 & $\begin{array}{l}\text { Extração de minério de ferro, inclusive beneficiamentos e a } \\
\text { aglomeraçáo }\end{array}$ & 0.81 & 0.73 & 0.57 & 0.29 & 0.43 \\
\hline 7 & $\begin{array}{l}\text { Extração de minerais metálicos não-ferrosos, inclusive } \\
\text { beneficiamentos }\end{array}$ & 1.25 & 0.72 & 0.09 & 0.16 & 0.13 \\
\hline 8 & $\begin{array}{l}\text { Abate e produtos de carne, inclusive os produtos do laticínio } \\
\text { e da pesca }\end{array}$ & 1.36 & 0.77 & 4.76 & 0.48 & 2.62 \\
\hline 9 & Fabricação e refino de açúcar & 1.30 & 0.70 & 0.94 & 0.34 & 0.64 \\
\hline 10 & Outros produtos alimentares & 1.26 & 0.95 & 3.74 & 1.05 & 2.40 \\
\hline 11 & Fabricação de bebidas & 1.16 & 0.71 & 0.72 & 0.49 & 0.60 \\
\hline 12 & Fabricação de produtos do fumo & 1.11 & 0.57 & 0.29 & 0.00 & 0.15 \\
\hline 13 & Fabricação de produtos têxteis & 1.13 & 0.94 & 0.29 & 0.52 & 0.41 \\
\hline 14 & Confecção de artefatos do vestuário e acessórios & 1.03 & 0.61 & 0.92 & 0.09 & 0.51 \\
\hline 15 & Fabricação de calçados e de artefatos de couro & 1.11 & 0.62 & 0.62 & 0.02 & 0.32 \\
\hline 16 & Fabricação de produtos da madeira & 1.05 & 0.76 & 0.09 & 0.40 & 0.24 \\
\hline 17 & Fabricaçáo de celulose, papel e produtos de papel & 1.16 & 1.07 & 0.45 & 0.80 & 0.62 \\
\hline
\end{tabular}




\begin{tabular}{|c|c|c|c|c|c|c|}
\hline \multirow{2}{*}{\multicolumn{2}{|c|}{ Setores }} & \multicolumn{2}{|c|}{$\begin{array}{l}\text { Índices de } \\
\text { ligaçáo HR }\end{array}$} & \multicolumn{3}{|c|}{$\begin{array}{c}\text { Índices puros de } \\
\text { ligaçáo }\end{array}$} \\
\hline & & BL & FL & PBL & PFL & PTL \\
\hline 18 & Impressão e reprodução de gravaçốes & 1.01 & 0.80 & 0.01 & 0.43 & 0.22 \\
\hline 19 & Refino de petróleo e coquerias & 1.37 & 2.48 & 2.15 & 3.71 & 2.93 \\
\hline 20 & Fabricação de biocombustíveis & 1.28 & 0.67 & 0.49 & 0.27 & 0.38 \\
\hline 21 & $\begin{array}{l}\text { Fabricação de químicos orgânicos e inorgânicos, resinas e } \\
\text { elastômeros }\end{array}$ & 1.17 & 1.80 & 0.40 & 1.96 & 1.18 \\
\hline 22 & $\begin{array}{l}\text { Fabricação de defensivos, desinfetantes, tintas e químicos } \\
\text { diversos }\end{array}$ & 1.13 & 1.08 & 0.23 & 1.02 & 0.62 \\
\hline 23 & $\begin{array}{l}\text { Fabricação de produtos de limpeza, cosméticos/perfumaria e } \\
\text { higiene pessoal }\end{array}$ & 1.19 & 0.62 & 0.65 & 0.13 & 0.39 \\
\hline 24 & Fabricação de produtos farmoquímicos e farmacêuticos & 0.98 & 0.64 & 0.55 & 0.23 & 0.39 \\
\hline 25 & Fabricação de produtos de borracha e de material plástico & 1.14 & 1.23 & 0.31 & 1.57 & 0.94 \\
\hline 26 & Fabricação de produtos de minerais não-metálicos & 1.12 & 0.86 & 0.17 & 1.57 & 0.87 \\
\hline 27 & $\begin{array}{l}\text { Produção de ferro-gusa/ferroligas, siderurgia e tubos de aço } \\
\text { sem costura }\end{array}$ & 1.17 & 1.22 & 0.45 & 1.60 & 1.03 \\
\hline 28 & Metalurgia de metais não-ferrosos e a fundição de metais & 1.24 & 0.94 & 0.36 & 0.62 & 0.49 \\
\hline 29 & $\begin{array}{l}\text { Fabricação de produtos de metal, exceto máquinas e } \\
\text { equipamentos }\end{array}$ & 1.10 & 1.04 & 0.48 & 1.31 & 0.89 \\
\hline 30 & $\begin{array}{l}\text { Fabricação de equipamentos de informática, produtos } \\
\text { eletrônicos e ópticos }\end{array}$ & 1.01 & 0.78 & 0.80 & 0.27 & 0.54 \\
\hline 31 & Fabricação de máquinas e equipamentos elétricos & 1.14 & 0.80 & 0.78 & 0.57 & 0.67 \\
\hline 32 & Fabricação de máquinas e equipamentos mecânicos & 1.10 & 0.92 & 1.63 & 0.47 & 1.05 \\
\hline 33 & Fabricação de automóveis, caminhôes e ônibus, exceto peças & 1.21 & 0.60 & 4.29 & 0.05 & 2.18 \\
\hline 34 & Fabricaçáo de peças e acessórios para veículos automotores & 1.14 & 0.89 & 0.48 & 1.25 & 0.87 \\
\hline 35 & $\begin{array}{l}\text { Fabricação de outros equipamentos de transporte, exceto } \\
\text { veículos automotores }\end{array}$ & 1.07 & 0.69 & 0.52 & 0.06 & 0.29 \\
\hline 36 & Fabricação de móveis e de produtos de indústrias diversas & 1.01 & 0.65 & 0.87 & 0.24 & 0.56 \\
\hline 37 & $\begin{array}{l}\text { Manutenção, reparação e instalação de máquinas e } \\
\text { equipamentos }\end{array}$ & 0.99 & 1.14 & 0.15 & 0.93 & 0.53 \\
\hline 38 & Energia elétrica, gás natural e outras utilidades & 1.16 & 1.71 & 0.73 & 2.05 & 1.39 \\
\hline 39 & Água, esgoto e gestáo de resíduos & 0.86 & 0.81 & 0.23 & 0.71 & 0.47 \\
\hline 40 & Construção & 1.02 & 0.94 & 7.84 & 0.91 & 4.38 \\
\hline 41 & $\begin{array}{l}\text { Comércio e reparação de veículos automotores e } \\
\text { motocicletas }\end{array}$ & 0.87 & 0.81 & 1.05 & 0.77 & 0.91 \\
\hline 42 & $\begin{array}{l}\text { Comércio por atacado e a varejo, exceto veículos } \\
\text { automotores }\end{array}$ & 0.85 & 3.57 & 4.65 & 6.73 & 5.69 \\
\hline 43 & Transporte terrestre & 1.10 & 2.15 & 1.75 & 3.56 & 2.65 \\
\hline 44 & Transporte aquaviário & 1.04 & 0.70 & 0.07 & 0.24 & 0.15 \\
\hline 45 & Transporte aéreo & 0.93 & 0.72 & 0.17 & 0.48 & 0.32 \\
\hline 46 & $\begin{array}{l}\text { Armazenamento, atividades auxiliares dos transportes e } \\
\text { correio }\end{array}$ & 0.87 & 1.33 & 0.28 & 1.50 & 0.89 \\
\hline 47 & Alojamento & 0.90 & 0.63 & 0.12 & 0.24 & 0.18 \\
\hline 48 & Alimentação & 1.00 & 0.71 & 2.62 & 0.62 & 1.62 \\
\hline
\end{tabular}




\begin{tabular}{|c|c|c|c|c|c|c|}
\hline \multirow{2}{*}{\multicolumn{2}{|c|}{ Setores }} & \multicolumn{2}{|c|}{$\begin{array}{l}\text { Índices de } \\
\text { ligaçáo HR }\end{array}$} & \multicolumn{3}{|c|}{$\begin{array}{c}\text { Índices puros de } \\
\text { ligaçáo }\end{array}$} \\
\hline & & \multirow{2}{*}{$\frac{\text { BL }}{1.02}$} & \multirow{2}{*}{$\frac{\text { FL }}{0.63}$} & \multirow{2}{*}{$\begin{array}{c}\text { PBL } \\
0.20\end{array}$} & \multirow{2}{*}{$\frac{\text { PFL }}{0.19}$} & \multirow{2}{*}{$\frac{\text { PTL }}{0.20}$} \\
\hline 49 & Edição e edição integrada à impressão & & & & & \\
\hline 50 & $\begin{array}{l}\text { Atividades de televisão, rádio, cinema e gravação/ediçâao de } \\
\text { som e imagem }\end{array}$ & 0.98 & 1.13 & 0.02 & 0.74 & 0.38 \\
\hline 51 & Telecomunicaçôes & 1.03 & 1.06 & 1.25 & 1.11 & 1.18 \\
\hline 52 & $\begin{array}{l}\text { Desenvolvimento de sistemas e outros serviços de } \\
\text { informaçáo }\end{array}$ & 0.79 & 0.92 & 0.36 & 1.02 & 0.69 \\
\hline 53 & $\begin{array}{l}\text { Intermediação financeira, seguros e previdência } \\
\text { complementar }\end{array}$ & 0.86 & 2.08 & 1.62 & 4.32 & 2.97 \\
\hline 54 & Atividades imobiliárias & 0.62 & 1.03 & 0.85 & 1.29 & 1.07 \\
\hline 55 & $\begin{array}{l}\text { Atividades jurídicas, contábeis, consultoria e sedes de } \\
\text { empresas }\end{array}$ & 0.80 & 1.81 & 0.14 & 2.83 & 1.48 \\
\hline 56 & $\begin{array}{l}\text { Serviços de arquitetura, engenharia, testes/análises técnicas } \\
\text { e P \& D }\end{array}$ & 0.82 & 0.93 & 0.21 & 0.91 & 0.56 \\
\hline 57 & Outras atividades profissionais, científicas e técnicas & 1.13 & 1.19 & 0.05 & 1.56 & 0.80 \\
\hline 58 & $\begin{array}{l}\text { Aluguéis não-imobiliários e gestão de ativos de propriedade } \\
\text { intelectual }\end{array}$ & 0.79 & 0.94 & 0.04 & 0.81 & 0.43 \\
\hline 59 & Outras atividades administrativas e serviços complementares & 0.79 & 1.44 & 0.33 & 2.86 & 1.59 \\
\hline 60 & Atividades de vigilância, segurança e investigação & 0.69 & 0.76 & 0.00 & 0.67 & 0.34 \\
\hline 61 & Administração pública, defesa e seguridade social & 0.78 & 0.74 & 4.90 & 0.40 & 2.65 \\
\hline 62 & Educação pública & 0.71 & 0.57 & 1.45 & 0.03 & 0.74 \\
\hline 63 & Educação privada & 0.80 & 0.64 & 0.66 & 0.20 & 0.43 \\
\hline 64 & Saúde pública & 0.81 & 0.56 & 1.37 & 0.01 & 0.69 \\
\hline 65 & Saúde privada & 0.86 & 0.61 & 1.29 & 0.01 & 0.65 \\
\hline 66 & Atividades artísticas, criativas e de espetáculos & 0.89 & 0.63 & 0.30 & 0.11 & 0.20 \\
\hline 67 & Organizaçôes associativas e outros serviços pessoais & 0.93 & 0.70 & 1.53 & 0.38 & 0.96 \\
\hline 68 & Serviços domésticos & 0.56 & 0.56 & 0.00 & 0.00 & 0.00 \\
\hline
\end{tabular}

Fonte: Matriz de Insumo-Produto do Brasil, 2013. Elaboração dos autores

No intuito de complementar a análise dos índices de ligação de $\mathrm{HR}$, dos índices puros e identificar os setores que mais influenciam as vendas e as compras do restante dos setores da economia, a Figura 2 apresenta o campo de influência da economia brasileira em 2013 em escala de cores ${ }^{7}$. Em outras palavras, é possível perceber as principais ligaçóes dentro de toda a estrutura produtiva.

7 A cor cinza mais clara indica aqueles coeficientes com influência maior do que a média da economia brasileira. O cinza intermediário mostra os coeficientes acima da média mais um desvio-padrão (DV), ao passo que a cor preta representa os coeficientes acima da média mais dois desvios-padrão (elos mais fortes). 
Figura 2- Campo de Influência para o Brasil - 2013

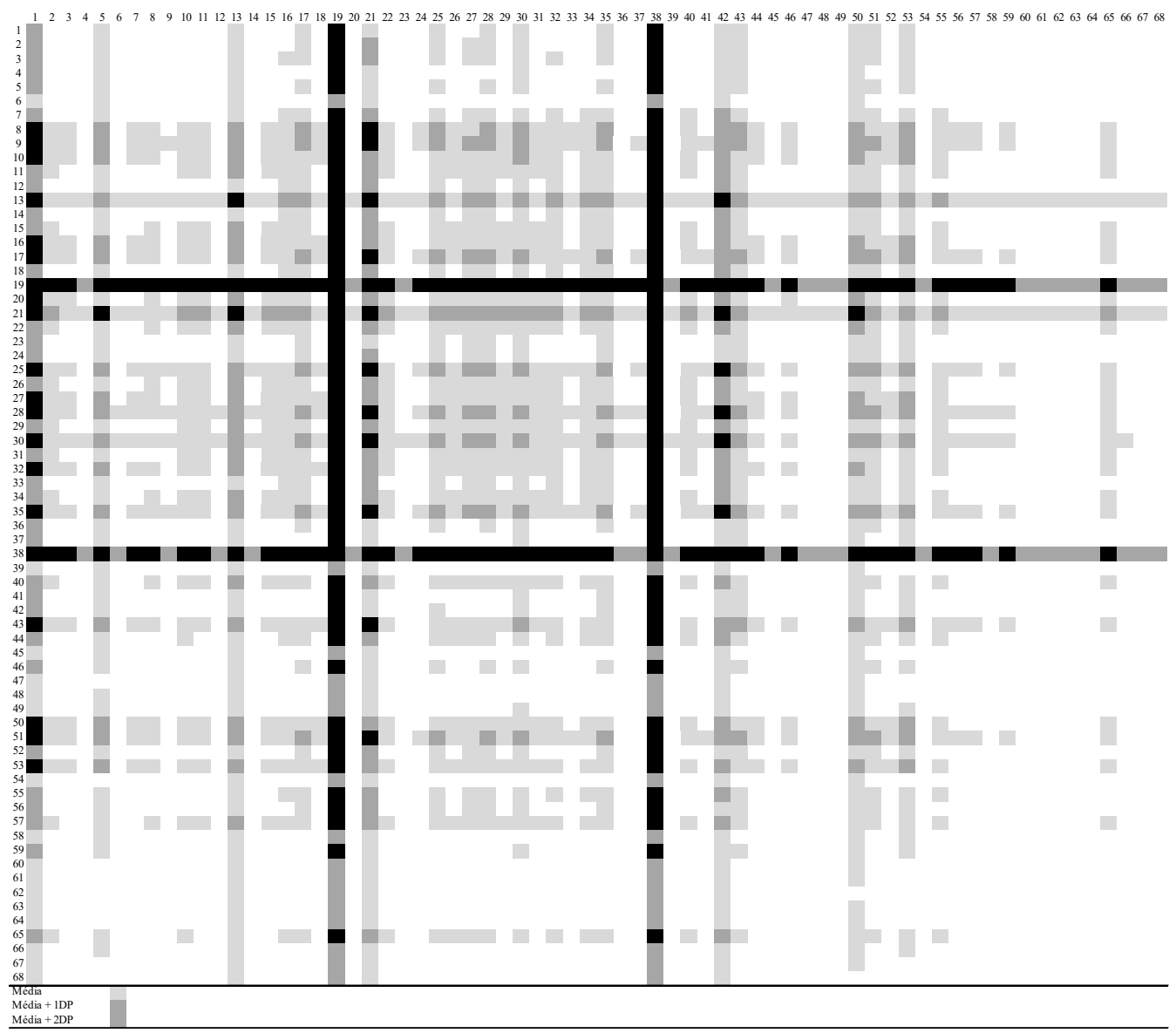

Fonte: Elaboração própria a partir da Matriz de Insumo-Produto do Brasil - 2013.

Desta forma, sob a ótica das compras (colunas da matriz), os setores que apresentam o maior campo de influência sobre os demais são: 1 - Agricultura, inclusive o apoio à agricultura e a pós-colheita, 19 - Refino de petróleo e 38 - Energia elétrica, gás natural e outras utilidades. Em relação aos setores vendedores (linhas da matriz), os que apresentam maior campo de influência são: 19 - Refino de petróleo e 38 - Energia elétrica, gás natural e outras utilidades. Cabe destacar que a maioria desses setores possui pelo menos um índice de ligação de HR maior do que 1. Este fato corrobora umas das características do campo de influência de que os setores que apresentam maiores índices de ligação, por conseguinte, também exercem maior influência sobre a compra de insumos e a venda de produtos dos demais setores.

Conforme citado anteriormente, o multiplicador do produto do setor $j$ pode ser definido como o total necessário de produção de todos os setores, para satisfazer a variação em uma unidade monetária da demanda total do setor $j$. Quanto maior for o multiplicador do produto, maiores seráo os efeitos de aumento na demanda final de um setor para a 
economia como um todo em termos de valor bruto da produção. De forma análoga, o multiplicador de emprego e renda apresentado na Tabela 03 corresponde ao número empregos criados e a renda adicional criada em toda a economia, respectivamente, quando se aumenta em uma R $\$ 1$ milhăo a demanda final do setor $j$.

Os maiores multiplicadores de produção, de acordo com a Tabela 03, são dos setores Abate e produtos de carne, inclusive os produtos do laticínio e da pesca $(2,46)$; Refino de petróleo e coquerias $(2,46)$; Fabricação e refino de açúcar $(2,34)$, Fabricação de biocombustíveis $(2,31)$ e Outros produtos alimentares $(2,77)$. Trata-se de setores industriais que participam da cadeia produtiva e impactam significativamente a produção, pois demandam muitos insumos para a sua produção e também fornecem insumos intermediários para outros setores. Para cada variação de $\mathrm{R} \$ 1$ da demanda final do setor de Refino de petróleo e coquerias, por exemplo, toda economia precisa produzir $\mathrm{R} \$ 2,46$ para atender esta variação de $\mathrm{R} \$$ da referida atividade.

No que tange aos setores que mais impulsionam a criação de empregos destacamse: Serviços domésticos (122); Pecuária, inclusive o apoio à pecuária (65); Confecção de artefatos do vestuário e acessórios (41); Produção florestal; pesca e aquicultura (38) e Organizações associativas e outros serviços pessoais (38). Para cada variação de $\mathrm{R} \$ 1$ milhão na demanda final da Pecuária, por exemplo, são criados 65 empregos diretos e indiretos na economia.

Diferentemente dos setores que se destacam com maiores multiplicadores de produto, os de emprego são basicamente do setor de serviços e da agropecuária, resultado que já era esperado uma vez que estes segmentos são intensivos em mão de obra.

Tabela 03: Multiplicadores da Produção, do Emprego e da Renda- 2013

\begin{tabular}{|c|c|c|c|c|}
\hline \multirow{2}{*}{\multicolumn{2}{|c|}{ Setores }} & \multicolumn{3}{|c|}{ Multiplicadores } \\
\hline & & \multirow{2}{*}{\begin{tabular}{|c|} 
Produto \\
1.63 \\
\end{tabular}} & \multirow{2}{*}{$\begin{array}{c}\text { Emprego } \\
27\end{array}$} & \multirow{2}{*}{$\begin{array}{c}\text { Renda } \\
0.19 \\
\end{array}$} \\
\hline 1 & Agricultura, inclusive o apoio à agricultura e a pós-colheita & & & \\
\hline 2 & Pecuária, inclusive o apoio à pecuária & 1.77 & 65 & 0.29 \\
\hline 3 & Produção florestal; pesca e aquicultura & 1.38 & 38 & 0.14 \\
\hline 4 & Extração de carvão mineral e de minerais não-metálicos & 1.81 & 13 & 0.35 \\
\hline 5 & Extração de petróleo e gás, inclusive as atividades de apoio & 1.44 & 4 & 0.20 \\
\hline 6 & $\begin{array}{l}\text { Extraçáo de minério de ferro, inclusive beneficiamentos e a } \\
\text { aglomeração }\end{array}$ & 1.46 & 4 & 0.18 \\
\hline 7 & Extração de minerais metálicos não-ferrosos, inclusive beneficiamentos & 2.24 & 12 & 0.42 \\
\hline 8 & Abate e produtos de carne, inclusive os produtos do laticínio e da pesca & 2.46 & 34 & 0.36 \\
\hline 9 & Fabricação e refino de açúcar & 2.34 & 23 & 0.38 \\
\hline 10 & Outros produtos alimentares & 2.27 & 21 & 0.34 \\
\hline 11 & Fabricação de bebidas & 2.08 & 13 & 0.34 \\
\hline 12 & Fabricação de produtos do fumo & 2.00 & 15 & 0.27 \\
\hline 13 & Fabricação de produtos têxteis & 2.03 & 26 & 0.40 \\
\hline 14 & Confecção de artefatos do vestuário e acessórios & 1.86 & 41 & 0.47 \\
\hline 15 & Fabricação de calçados e de artefatos de couro & 1.99 & 26 & 0.45 \\
\hline 16 & Fabricação de produtos da madeira & 1.89 & 29 & 0.41 \\
\hline
\end{tabular}




\begin{tabular}{|c|c|c|c|c|}
\hline \multirow{2}{*}{\multicolumn{2}{|c|}{ Setores }} & \multicolumn{3}{|c|}{ Multiplicadores } \\
\hline & & \multirow{2}{*}{$\begin{array}{c}\text { Produto } \\
2.09\end{array}$} & \multirow{2}{*}{\begin{tabular}{|c|} 
Emprego \\
13
\end{tabular}} & \multirow{2}{*}{$\frac{\text { Renda }}{0.35}$} \\
\hline 17 & Fabricação de celulose, papel e produtos de papel & & & \\
\hline 18 & Impressão e reprodução de gravaçôes & 1.81 & 17 & 0.42 \\
\hline 19 & Refino de petróleo e coquerias & 2.46 & 6 & 0.21 \\
\hline 20 & Fabricação de biocombustíveis & 2.31 & 20 & 0.33 \\
\hline 21 & Fabricação de químicos orgânicos e inorgânicos, resinas e elastômeros & 2.10 & 7 & 0.25 \\
\hline 22 & Fabricação de defensivos, desinfestantes, tintas e químicos diversos & 2.04 & 9 & 0.32 \\
\hline 23 & $\begin{array}{l}\text { Fabricação de produtos de limpeza, cosméticos/perfumaria e higiene } \\
\text { pessoal }\end{array}$ & 2.13 & 13 & 0.35 \\
\hline 24 & Fabricação de produtos farmoquímicos e farmacêuticos & 1.76 & 9 & 0.34 \\
\hline 25 & Fabricação de produtos de borracha e de material plástico & 2.05 & 13 & 0.39 \\
\hline 26 & Fabricação de produtos de minerais não-metálicos & 2.02 & 16 & 0.40 \\
\hline 27 & Produção de ferro-gusa/ferroligas, siderurgia e tubos de aço sem costura & 2.11 & 9 & 0.32 \\
\hline 28 & Metalurgia de metais não-ferosos e a fundiçáo de metais & 2.23 & 11 & 0.36 \\
\hline 29 & Fabricação de produtos de metal, exceto máquinas e equipamentos & 1.98 & 15 & 0.43 \\
\hline 30 & $\begin{array}{l}\text { Fabricação de equipamentos de informática, produtos eletrônicos e } \\
\text { ópticos }\end{array}$ & 1.81 & 9 & 0.29 \\
\hline 31 & Fabricação de máquinas e equipamentos elétricos & 2.06 & 11 & 0.40 \\
\hline 32 & Fabricação de máquinas e equipamentos mecânicos & 1.97 & 12 & 0.42 \\
\hline 33 & Fabricação de automóveis, caminhóes e ônibus, exceto peças & 2.18 & 10 & 0.36 \\
\hline 34 & Fabricação de peças e acessórios para veículos automotores & 2.06 & 12 & 0.44 \\
\hline 35 & $\begin{array}{l}\text { Fabricação de outros equipamentos de transporte, exceto veículos } \\
\text { automotores }\end{array}$ & 1.92 & 10 & 0.40 \\
\hline 36 & Fabricação de móveis e de produtos de indústrias diversas & 1.82 & 21 & 0.38 \\
\hline 37 & Manutenção, reparação e instalação de máquinas e equipamentos & 1.78 & 16 & 0.37 \\
\hline 38 & Energia elétrica, gás natural e outras utilidades & 2.09 & 6 & 0.25 \\
\hline 39 & Água, esgoto e gestão de resíduos & 1.54 & 15 & 0.36 \\
\hline 40 & Construçáo & 1.84 & 21 & 0.38 \\
\hline 41 & Comércio e reparação de veículos automotores e motocicletas & 1.56 & 25 & 0.40 \\
\hline 42 & Comércio por atacado e a varejo, exceto veículos automotores & 1.53 & 24 & 0.42 \\
\hline 43 & Transporte terrestre & 1.97 & 19 & 0.38 \\
\hline 44 & Transporte aquaviário & 1.87 & 10 & 0.44 \\
\hline 45 & Transporte aéreo & 1.68 & 8 & 0.33 \\
\hline 46 & Armazenamento, atividades auxiliares dos transportes e correio & 1.57 & 14 & 0.50 \\
\hline 47 & Alojamento & 1.62 & 26 & 0.47 \\
\hline 48 & Alimentação & 1.79 & 32 & 0.34 \\
\hline 49 & Edição e edição integrada à impressão & 1.84 & 16 & 0.50 \\
\hline 50 & $\begin{array}{l}\text { Atividades de televisão, rádio, cinema e gravação/edição de som e } \\
\text { imagem }\end{array}$ & 1.76 & 12 & 0.44 \\
\hline 51 & Telecomunicaçôes & 1.84 & 10 & 0.30 \\
\hline 52 & Desenvolvimento de sistemas e outros serviços de informação & 1.42 & 11 & 0.45 \\
\hline 53 & Intermediação financeira, seguros e previdência complementar & 1.54 & 7 & 0.42 \\
\hline 54 & Atividades imobiliárias & 1.11 & 2 & 0.04 \\
\hline 55 & Atividades jurídicas, contábeis, consultoria e sedes de empresas & 1.44 & 14 & 0.39 \\
\hline 56 & Serviços de arquitetura, engenharia, testes/análises técnicas e P \& D & 1.48 & 13 & 0.42 \\
\hline
\end{tabular}




\begin{tabular}{c|l|c|c|c}
\hline \multicolumn{2}{c|}{ Setores } & \multicolumn{3}{c}{ Multiplicadores } \\
\cline { 3 - 5 } \multicolumn{2}{l|}{} & Produto & Emprego & Renda \\
\hline 57 & Outras atividades profissionais, científicas e técnicas & 2.03 & 15 & 0.38 \\
\hline 58 & Aluguéis não-imobiliários e gestáo de ativos de propriedade intelectual & 1.42 & 11 & 0.30 \\
\hline 59 & Outras atividades administrativas e serviços complementares & 1.43 & 27 & 0.56 \\
\hline 60 & Atividades de vigilância, segurança e investigação & 1.24 & 28 & 0.75 \\
\hline 61 & Administraçáo pública, defesa e seguridade social & 1.40 & 13 & 0.72 \\
\hline 62 & Educaçáo pública & 1.28 & 20 & 0.84 \\
\hline 63 & Educaçáo privada & 1.44 & 32 & 0.70 \\
\hline 64 & Saúde pública & 1.46 & 18 & 0.75 \\
\hline 65 & Saúde privada & 1.54 & 23 & 0.45 \\
\hline 66 & Atividades artísticas, criativas e de espetáculos & 1.59 & 35 & 0.41 \\
\hline 67 & Organizaçóes associativas e outros serviços pessoais & 1.67 & 38 & 0.44 \\
\hline 68 & Serviços domésticos & 1.00 & 122 & 1.00 \\
\hline
\end{tabular}

Fonte: Elaboração própria a partir da Matriz de Insumo-Produto do Brasil - 2013.

Os setores mais relevantes por impactar a renda das famílias, ou seja, por possuir um elevado multiplicador de renda são: Serviços domésticos $(1,00)$; Educaçáo pública $(0,84)$; Atividades de vigilância, segurança e investigação $(0,75)$; Saúde pública $(0,75)$ e Administração pública, defesa e seguridade social $(0,72)$. Para cada variação de $\mathrm{R} \$ 1$ na demanda final do setor de Educaçâo Pública, por exemplo, é gerado R \$ 0,84 centavos de renda adicional na economia brasileira. De forma geral, percebe-se uma heterogeneidade dos resultados entre os setores.

\section{CONSIDERAÇÓES FINAIS}

A experiência brasileira de planejamento, referenciada nos planos econômicos, é bastante conturbada tanto em relação a elaboração quanto a implementação. A visão setorial vigente até meados dos anos 50 é ampliada a partir da década de 60 quando o desenvolvimento econômico passa a ter um tratamento global, a partir da inserção de novos setores e da consideração de aspectos sociais, administrativos, institucionais e geopolíticos (MENDES, 1978).

Associado a esse panorama o método de análise via os modelos de insumo-produto foi aprimorado podendo ser útil como instrumento eficaz de planejamento, auxiliando na formulação de políticas públicas na medida em que direcionam investimentos de forma mais eficiente, não só espacialmente, mas também, setorialmente. De posse disso e a partir da Matriz de Insumo-Produto, ano base 2013, o presente estudo teve como objetivo oferecer subsídios ao planejamento econômico no Brasil, a partir da técnica de insumo-produto.

A análise conjunta dos índices de HR, dos índices puros de ligação e do campo de influência, evidenciam que, dos 68 setores constituintes da MIP brasileira, 15 atividades apresentaram encadeamentos intersetoriais acima da média, com destaque para Refino de petróleo e coquerias, Transporte terrestre, Energia elétrica e Telecomunicaçóes, pois apareceram, simultaneamente, em mais de uma abordagem. Esses setores têm a capacidade de alavancar a economia brasileira mais rapidamente, afetando, quando estimulados, 
um maior número de outros setores. Desta forma, as atividades de maior potencial de encadeamento setorial devem ser priorizadas como alvos nas políticas de indução do crescimento econômico. Em relação aos multiplicadores de impacto, percebeu-se que o Abate e produtos de carne e Serviços domésticos apresentaram melhores resultados em relação à geração de produto e renda, respectivamente, ao passo que setores ligados a serviços e a agropecuária destacaram-se na criação de empregos.

Dada a complexidade do sistema econômico sugere-se que as insuficiências do modelo de insumo-produto atreladas às suposiçóes implícitas de oferta perfeitamente elástica e retornos constantes de escala, sejam tratadas em estudos futuros com o modelo de equilíbrio geral computável. Este desponta como uma evolução daquele, sendo habilitado a captar com mais propriedade os feitos sobre a demanda, sejam eles exógenos ou endógenos em termos de mudanças de preços e avanços tecnológicos (MILLER e BLAIR, 2009).

Uma das principais conclusóes do trabalho que reforça a ideia de que os 15 setores destacados acima favorecem a condução de políticas de planejamento e setoriais como forma de fomentar regiôes mais estagnadas e vazias. Tal resultado propóe que políticas transversais, como às de fomento à inovação, permitam selecionar e apoiar setores capazes de trazer soluçóes para os problemas mais complexos da economia brasileira, como a desigualdade regional.

Em que pesem as limitaçóes metodológicas inerentes às suposiçóes do modelo Insumo-Produto, os resultados elucidados no presente estudo servem como indícios empíricos capazes de subsidiar e orientar as intervenções por parte do governo. Além de auxiliar os demais agentes econômicos envolvidos na formulação de políticas públicas, de modo que os recursos sejam alocados eficientemente e direcionado a setores que respondam estrategicamente aos incentivos impulsionadores de crescimento. Assim, os resultados apurados incitam algumas sugestóes de políticas públicas relevantes ao planejamento econômico brasileiro e salientados no referencial teórico, sendo destacados nos seguintes pontos:

1- Reforço da base tecnológica brasileira, para que os setores industriais sejam capazes de produzir tecnologia de fronteira e de competir em condiçóes de igualdade com os melhores mercados mundiais.

2- Outro resultado que pode subsidiar políticas de planejamento é relativo ao impacto dos investimentos em P\&D nos setores de Agricultura, Transporte, Energia e Telecomunicaçóes, e utilizar esses investimentos para resolver os problemas relacionados à eficiência energética (reduzindo o consumo de água); desenvolvimento de tecnologias de despoluição; aprimoramento dos transportes urbanos e inter-regionais, assim como toda a infraestrutura dos diferentes modais de transporte, entre outros.

3- Compete à política regional selecionar os setores ou indústrias privilegiadas pela política de planejamento, de acordo com o grau de encadeamento setorial encontrado. Para o desenvolvimento de áreas mais competitivas, as políticas de desenvolvimento regional deveriam criar condiçóes profícuas que estivessem de acordo com a política de planejamento daquela localidade. 
Por fim, no intuito de futuras contribuições à literatura na área de planejamento, poder-se-ia examinar os efeitos regionais de políticas públicas e setoriais específicas. Além disso, estudos mais aprofundados utilizando a metodologia da Matriz Insumo-Produto regional permitiria uma investigação mais detalhada do planejamento político e regional brasileiro, apontando suas potencialidades e fragilidades.

\section{REFERÊNCIAS}

BELO, G. C., RIBEIRO, L. C. S., SIMOES, R. O impacto da construção do Complexo Industrial e Portuário de Açu no Norte Fluminense. Revista Brasileira de Estudos Regionais e Urbanos, v. 11, p. 173-192, 2017.

BERNARDES, L. Política urbana: uma análise da experiência brasileira. Análise e Conjuntura, v.1, n.1. Belo Horizonte: Fundação João Pinheiro, 1986

CAMPBELL, S., FAINSTEIN, S. Introduction: the structure and debates of planning theory. In: Campbell, S., Fainstein S. (Edits.) Readings in Planning Theory: Malden, MA: Blackwell Publishers, 1996.

CARDOSO, F. H. Aspectos políticos do planejamento. In: Lafer, B. M. Planejamento no Brasil. São Paulo: Editora Perspectiva, 1975

CARVALHO, J. T. A., SANTOS, G. F., MATA, H. T. C., RIBEIRO, L. C. S. Sustentabilidade e rotas tecnológicas de reciclagem para a cidade de Salvador no âmbito da Política Nacional de Resíduos Sólidos. Planejamento e Politicas Publicas, 2018 (no prelo).

DE NEGRI, F. Por uma nova geração de políticas de inovação no Brasil. In: Políticas de apoio à inovaçáo tecnológica no Brasil: avanços recentes, limitaçóes e propostas de açóes. ORGS:. TURCHI, L. M., DE MORAIS, J. M - Brasília: IPEA, 2017.

FREITAS, L. F. S., RIBEIRO, L. C. S., SOUZA, K. B., HEWINGS, G. J. The distributional effects of emissions taxation in Brazil and their implications for climate policy. Energy Economics, v. 59, p. 37-44, 2016.

GUILHOTO, J. J. M. et al. Índices de ligaçóes e setores-chave na economia brasileira: 1959-1980. Pesquisa e Planejamento Econômico: Rio de Janeiro, v. 24, n. 2, p. 287314, 1994.

GUILHOTO, J. J. M., SESSO FILHO, U. A. Estimação da matriz insumo-produto a partir de dados preliminares das contas nacionais. Economia Aplicada, v. 9, n. 2, p. $277-$ 299, 2005. 
GUILHOTO, J. J. M., SESSO FILHO, U. A. Estimação da Matriz Insumo-Produto utilizando dados preliminares das Contas Nacionais: Aplicação e análise de indicadores econômicos para o Brasil em 2005. Economia \& Tecnologia, v. 23, n. 6, 2010.

GUILHOTO, J. J. M., SONIS, M., HEWINGS, G. J. D. Linkages and Multipliers in a Multiregional Framework: Integration of Alternative Approaches. Australasian Journal of Regional Studies, v.11, n. 1, 2005.

GUILHOTO, J. J. M., AZZONI, C. R., ICHIHARA, S. M., KADOTA, D. K., HADDAD, E. A. Matriz de Insumo-Produto do Nordeste e Estados: Metodologia e Resultados. Fortaleza: Banco do Nordeste do Brasil, 2010.

HADDAD, E. A. A estrutura econômica de Minas Gerais: uma análise de insumoproduto. Nova Economia, Belo Horizonte, VIII Prêmio Minas de Economia, 1995.

HADDAD, E. A., PORSSE, A. A., RABAHY, W. A. Domestic tourism and regional inequality in Brazil. Tourism Economics, v. 19, n. 1, p. 173-186, 2013.

HALL, P. G. Cidades do amanhá: uma história intelectual do planejamento e do projeto urbanos do século XX. São Paulo: Perspectiva, 2002.

HEALEY, P. Collaborative planning. Houdmills: Palgrave Macmillan, 2005.

HIRSCHMAN, A. O. The strategy of economic development. USA, Yale University, 1958.

IPEA - Instituto de Pesquisa Econômica Aplicada. Pesquisa sobre pagamento por serviços ambientais urbanos para a gestáo de resíduos sólidos. Relatório de Pesquisa. 2010 .

LAFER, B. M. O conceito de planejamento. In: Lafer, B. M. Planejamento no Brasil. São Paulo: Editora Perspectiva, 1975.

LEONTIEF, W. The Structure of the American Economy. Segunda Ediçẫo Ampliada. New York: Oxford University Press, 1951.

LEONTIEF, W. Input-Output Economics. New York: Oxford University Press, 1966.

LEONTIEF, W. Input-Output Analysis. In: Eatwell, J., M. Milgate, e P. Newman (eds.). The New Palgrave. A Dictionary of Economics, v. 2., p. 860-64, 1987.

MAIA, J, M. Economia Internacional e Comércio Exterior. 16a edição. Editora Atlas, São Paulo, 2014. 
MENDES, A. G. A experiência de planejamento econômico no Brasil. In: Cintra, A. O.; Haddad, P. R. Dilemas de planejamento urbano e regional no Brasil. Rio de Janeiro: Zahar, 1978.

MENEZES FILHO, N., KOMATSU, B.,LUCCHESI, A., FERRARIO, M. Políticas de inovação no Brasil. Policy Paper, n. 11. Insper Centro de Políticas Públicas: Agosto de 2014

MILLER, R. E., BLAIR, P. D. Input-output analysis: foundations and extensions. 2th ed. New York: Cambridge University Press, 2009.

PRADO, E. F. S. Estrutura tecnológica e desenvolvimento regional. São Paulo: USP, 1981.

RASMUSSEN, P. Studies in intersectorial relations. Holanda: North Holland, 1956.

RIBEIRO, L. C. S., ANDRADE, J. R. L., POSSAS, G. Impactos económicos de los gastos turísticos en Sergipe y sus efectos colaterales en el resto de Brasil. Estudios y Perspectivas en Turismo, v. 23, p. 447-466, 2014 a.

RIBEIRO, L. C. S., FREITAS, L. F. S., CARVALHO, J. T. A., OLIVEIRA FILHO, J. D. . Aspectos econômicos e ambientais da reciclagem: um estudo exploratório nas cooperativas de catadores de material reciclável do Estado do Rio de Janeiro. Nova Economia, v. 24, p. 191-214, 2014 b.

RIBEIRO, L. C. S., LEITE, A. V. P. Estrutura econômica do estado de Sergipe em 2006: uma contribuição através da matriz de insumo-produto. Revista Econômica do Nordeste, v. 43, p. 95-117, 2012.

RIBEIRO, L. C. S., LEITE, A. V. P. Análise estrutural dos investimentos do PAC em infraestrutura logística no estado da Bahia. Análise Econômica, v. 32, p. 125-154, 2014.

RIBEIRO, L. C. S., SILVA, E. O. V., ANDRADE, J. R. L., SOUZA, K. B. Tourism and regional development in the Brazilian Northeast. Tourism Economics, v. 23, p. 717-727, 2017.

ROCHA NETO, J. M., BORGES, D. F. As assimetrias entre as políticas setoriais e a política de planejamento regional no Brasil. Rev. Adm. Pública, v.45, n.6, 2011.

ROSSETI, J. P. Política e Programaçáo Econômicas. São Paulo: Atlas, 1974.

SNA. System of National Accounts. Inter-Secretariat Working Group on National Accounts. Bruxelas, 1993. 
SONIS, M., HEWINGS, G. J. D. Error and sensitivity input-output analysis: A new approach. In: Miller, R. E et al. (Ed.) Frontiers of input-output analysis. New York: Oxford University Press, 1989.

SOUZA, M. L. Mudar a cidade: uma introduçáo crítica ao planejamento e à gestáo urbanos. Rio de Janeiro: Bertrand Brasil, 2006.

STONE, R. Input-output and demographic accounting: A tool for education planning. Minerva, IV, 3, p.365-380, 1968.

STONE, R. Input-output Analysis and economic planning: A Survey. Revista de Econometria, 1984.

VAINER, C. B. Planejamento territorial e projeto nacional: os desafios da fragmentação. Revista Brasileira de Estudos Urbanos e Regionais, v.9, n.1, 2007.

VALE, V. A., PEROBELLI, F. S., CHIMELI, A. B. International trade, pollution, and economic structure: evidence on CO2 emissions for the North and the South. Economic Systems Research, 2017. Doi: http://dx.doi.org/10.1080/09535314.2017.136190. 